\title{
Os Efeitos do Novo Regionalismo sobre o Comércio
}

\author{
Magnus dos Reis \\ Doutorando - Universidade Federal do Rio Grande do Sul - Faculdade de Ciências Econômicas \\ Endereço: Av. João Pessoa, 52 sala 33 B, $3^{\circ}$ andar - Porto Alegre/RS - Brasil - CEP: 90040-000 \\ E-mail: magnusdosreis@hotmail.com
}

\section{André Filipe Zago de Azevedo}

Professor - Universidade do Vale do Rio dos Sinos - Programa de Pós-Graduação em Economia Endereço: Av. Unisinos, 950, sala 5 A, 406 d - São Leopoldo/RS - Brasil - CEP 93022-000

E-mail: aazevedo@unisinos.br

\section{Marcos Tadeu Caputi Lélis}

Professor - Universidade do Vale do Rio dos Sinos - Programa de Pós-Graduação em Economia Endereço: Av. Unisinos, 950, sala 5 A, 403 c - São Leopoldo/RS - Brasil - CEP $93022-000$

E-mail: mlelis@unisinos.br

Recebido em 29 de outubro de 2012. Aceito em 03 de fevereiro de 2014.

\section{Resumo}

A partir de 1990 ocorreu um "boom" na formação de blocos econômicos no mundo, e este trabalho procurou identificar se o regionalismo propiciou criação ou desvio de comércio. Para isto, utilizou-se o modelo gravitacional com dados em painel para o período de 1990 a 2009. Os resultados sugerem que houve criação de comércio e desvio de exportação no Mercosul. Além disso, percebe-se o efeito antecipação sobre os fluxos de comércio intrazona e sinais de criação de comércio com a formação do NAFTA. De forma distinta, há indícios de que o Asean e o PAFTA desviaram comércio. Por fim, a forma como evoluíram os fluxos de comércio intrazona (ex ante e ex post) decorrentes da constituição dos blocos analisados foi diferente não somente em termos de volume, mas também na velocidade em que eles responderam a sua formação.

\section{Palavras-Chave}

integração regional, modelo gravitacional, dados em painel

\begin{abstract}
From 1990 there was a proliferation of Preferential Trade Agreements notified to the World Trade Organization and this study aims to identify whether this new regionalism led to trade creation or trade diversion to their participants, using a gravity model based on panel data over the period 1990-2009. The results suggest the existence of trade creation and export diversion due to the formation of Mercosur. With regards to NAFTA, besides being the only bloc that showed an anticipatory effect on their trade flows within the region, there are signs that the growth of trade occurred due to trade creation. Nevertheless, there are indications that the Asean and PAFTA caused trade diversion. Finally, the way that trade flows evolved within each bloc (ex ante and ex post) was quite different, not only in terms of trade volume but also on how quickly they responded to their formation, with its effects arising immediately in some cases and in others taking a few years.
\end{abstract}




\section{Keywords}

regional integration, gravity model, panel data

\section{JEL Classification}

F15, C23, C21

\section{Introdução}

O aumento do número de Acordos Preferenciais de Comércio (APC) nas últimas décadas foi algo sem precedentes. Entre as décadas de 1950 e 1980, apenas 22 APC foram notificados à Organização Mundial de Comércio (OMC), ao passo que, no período 1990-2009, foram criados 175 novos acordos. No entanto, o regionalismo não é um fenômeno recente. Segundo Bhagwati et al. (1999), a primeira onda de regionalismo ocorreu no século $\mathrm{XX}$, mais especificamente no final da década de 1950 e durante a década de 1960. Ela envolvia apenas setores industriais específicos, removia unicamente as barreiras de importação, era composta somente por países com o mesmo nível de desenvolvimento e dirigida pelos governos, baseando-se, em muitos APC, na política de substituição de importações. Já a segunda onda, que ocorre a partir dos anos 1990, envolve quase todos os setores, inclui países com diferentes níveis de desenvolvimento, disciplinas comuns para regimes regulatórios e tem sido liderada pelas empresas, ao buscarem novos mercados para suas exportações. Nesse sentido, a segunda onda do regionalismo proporciona uma integração mais profunda em comparação à primeira.

Com este boom do regionalismo, a preocupação dos economistas com os possíveis efeitos prejudiciais que a integração econômica pode causar também cresceu e, dessa forma, conhecer as consequências dessa integração sobre os fluxos de comércio se torna importante. No entanto, Viner (1950) já estava interessado em tal questão em 1950.

Ele afirmou que o impacto dos APC sobre o bem-estar dos países depende da existência de criação ou desvio de comércio. Assim, a integração econômica pode causar resultados favoráveis ou nocivos aos países que a compõe. Os APC poderiam ser considerados prejudiciais para os países membros e para o resto do mundo quando eles produzirem desvio de comércio e benéficos quando produzirem 
criação de comércio. ${ }^{1}$ No entanto, conforme sugerido por Winters (1997), exercícios de criação (desvio) de comércio são apenas medidas indicativas e não medidas definitivas de ganhos (perdas) de bem-estar.

Desde Viner (1950), diferentes metodologias têm sido utilizadas para mensurar a criação e o desvio de comércio. Alguns pesquisadores utilizaram estatísticas descritivas, como a análise conjunta dos índices de Orientação Regional e de Vantagem Comparativa Revelada, sugeridos por Yeats (1997). Entretanto, tal abordagem está sujeita a críticas, uma vez que não faz uma análise contrafactual, de um mundo onde os APC não tivessem sido formados, para avaliar seus resultados. Outros autores recorreram aos modelos de Equilíbrio Geral Computável (EGC). Tais modelos fazem uma análise ex ante dos acordos regionais, utilizando o padrão de comércio e as elasticidades conhecidas (ou estimadas) para prever os efeitos da eliminação de barreiras tarifárias e não tarifárias sobre os fluxos comerciais. No entanto, tal técnica pode ser considerada um procedimento ad hoc, pois caso as elasticidades de substituição não reflitam a realidade, seus resultados podem ser viesados. Além disso, conforme Wylie apud Magee (2008), os modelos de EGC têm perdido espaço entre os pesquisadores para mensurar os efeitos dos blocos econômicos.

Por outro lado, o modelo gravitacional é capaz de explicar, de forma muito satisfatória, os fluxos de comércio bilateral entre os países mesmo se os APC não tivessem sido formados e isto explica, em grande parte, sua ampla utilização. Além disso, ele permite avaliar não somente os impactos causados sobre os fluxos de comércio bilaterais que possam ser atribuídos exclusivamente à formação dos APC, mas também se eles criaram ou desviaram comércio. Assim, fazendo uso dessa metodologia, este artigo busca respostas sobre quais foram os impactos do novo regionalismo sobre os fluxos de comércio.

\footnotetext{
A criação de comércio ocorre quando há substituição da produção doméstica por importações de parceiros preferenciais mais eficientes devido à formação do bloco. Isso proporcionaria uma melhor alocação de recursos, pois os fatores de produção domésticos que estiverem ociosos, uma vez que a produção doméstica foi substituída por importações de um país parceiro, poderiam migrar para atividades nas quais o país possuísse vantagem comparativa em relação aos demais. Diferentemente, o desvio de comércio ocorre quando há substituição de importações extrabloco por importações intrabloco que são menos eficientes em comparação aos países de fora do bloco. Viner (1950) concluiu que a criação de comércio melhoraria o bem-estar, enquanto o desvio de comércio o reduziria. Alguns autores fizeram qualificações a respeito dessa ligação direta entre criação/desvio de comércio e os efeitos sobre o bem-estar (por exemplo, Lipsey, 1957; Meade, 1955; Panagariya, 1996).
} 
Mais especificamente, o objetivo é identificar se eles criaram ou desviaram comércio, quais foram as consequências sobre os fluxos de comércio intrabloco e extrabloco e, por fim, a partir de quanto tempo esses efeitos seriam observados em cada acordo e qual a sua duração.

O artigo está dividido em seis seções, incluindo esta introdução. A seção 2 faz uma revisão do modelo gravitacional, demonstrando seus desenvolvimentos mais recentes e ressaltando as especificações e os estimadores que já foram utilizados. A seção 3 demonstra a origem e o tratamento dos dados, enquanto a seção 4 apresenta os modelos a serem estimados e as variáveis utilizadas. A seção 5 exibe os resultados encontrados e os testes de especificação que foram submetidos os modelos. Por fim, a seção 6 apresenta as conclusões.

\section{O Modelo Gravitacional}

O modelo gravitacional tem origem na lei da gravitação universal de Isaac Newton, formulada na metade do século XVII. No século XIX, Tinbergen (1962), Poyhonen (1963) e Linnemann (1966) adaptaram a lei da gravidade à economia para estimar o fluxo de comércio bilateral entre dois países. Foram esses autores que propuseram o modelo gravitacional ao fornecer as variáveis básicas que são utilizadas, em alguns casos, até hoje para determinar o comércio bilateral entre os países. O modelo gravitacional parte da ideia básica de que o comércio entre dois países é diretamente proporcional ao Produto Interno Bruto (PIB) de suas economias e inversamente proporcional à distância entre eles. Sua forma mais simples pode ser descrita da seguinte maneira:

$\ln m_{i j}=\beta_{0}+\beta_{1} \ln Y_{i}+\beta_{2} \ln \left(\frac{Y_{i}}{N_{i}}\right)+\beta_{3} \ln Y_{j}+\beta_{4} \ln \left(\frac{Y_{j}}{N_{j}}\right)+\beta_{5} \ln$ dist $_{i j}+\varepsilon_{i j}$

onde:

$m_{i j}$ representa as importações bilaterais entre os países $i$ e $j$;

$Y_{w}$ é o PIB dos países $i$ e $j$;

$N_{w}$ é a população dos países $i$ e $j$;

dist $_{i j}$ é a distância entre os países $i$ e $j$;

$\varepsilon_{i j}$ é o erro.

Estud. Econ., São Paulo, vol. 44, n.2, p. 351-381, abr.jun. 2014 
Com o passar dos anos, os pesquisadores perceberam que outros fatores poderiam afetar o volume de comércio bilateral e, por isso, passaram a incluir na equação gravitacional outras variáveis, a fim de aumentar o poder de explicação do modelo. Nesse sentido, dummies foram inseridas para representar algumas características que se presumia que também afetassem o volume de comércio entre os países. Por exemplo, espera-se que países com um idioma oficial em comum e que partilhem uma fronteira tenham maiores facilidades de negociar e, sendo assim, apresentem um volume de comércio maior em comparação aos países que não apresentem tais características. Além disso, Aitken (1973) foi um dos pioneiros a avaliar o impacto da criação dos APC sobre os fluxos de comércio. Nesse caso, o modelo gravitacional refletia o comércio "normal" entre dois países sem a presença de um APC, enquanto a variável dummy relacionada ao APC captava o comércio que podia ser atribuído exclusivamente à criação do mesmo.

Soloaga e Winters (2001) foram os pioneiros na inclusão de três variáveis dummies para cada bloco, sendo uma delas para capturar o efeito da criação do APC sobre o comércio intrabloco, outra para as importações totais do bloco e a última para as exportações totais do bloco. Através da inserção dessas variáveis, esses autores conseguiram analisar não somente o impacto sobre o fluxo de comércio bilateral que pode ser exclusivamente atribuído à formação do bloco, mas também se houve criação ou desvio de comércio com a formação do mesmo, bem como se ocorreu o que ambos os autores denominaram de "desvio de exportação".

Até esse período, grande parte dos trabalhos realizados estimou o modelo gravitacional com dados em cross-section ou dados agrupados (pooled data) e através do estimador de Mínimos Quadrados Ordinários (MQO). Esta arquitetura pode ser considerada a abordagem tradicional do modelo. Entretanto, a teoria econômica internacional avançou e novos conceitos sobre o regionalismo foram desenvolvidos. Um deles foi proposto por Wonnacott e Lutz (1989), Summers (1991) e Krugman (1991), ao criarem o conceito de "parceiro natural de comércio" para países próximos geograficamente e que possuam elevados níveis de comércio bilateral. Esse novo conceito teve um impacto direto sobre a forma que vinha sendo mensurada a criação e o desvio de comércio. Como os APC são representados por variáveis dummies, tais variáveis podem capturar mais que o 
efeito do acordo, isto é, existe a possibilidade de que a dummy sofra influência de outros fatores que não somente o APC, tais como laços históricos, culturais ou políticos, bem como a possibilidade de que os membros do bloco sejam parceiros naturais de comércio. Assim, pode ocorrer super ou subestimação dos coeficientes relacionados à dummy do bloco, considerando a abordagem tradicional.

Não obstante, Anderson e Van Wincoop (2003) afirmaram que o modelo gravitacional usual pode apresentar problemas de especificação ao ignorar a "resistência multilateral" e "isolamento" dos países. Além disso, segundo Egger (2005), o modelo gravitacional com dados agrupados e em cross-section sofre problemas de especificação, uma vez que ele não é capaz de lidar com a heterogeneidade bilateral do exportador e importador, que é extremamente provável que esteja presente nos fluxos de comércio bilaterais. Matyas (1997) e Anderson e Van Wincoop (2003) sugerem a estimação da equação gravitacional em dados em painel e efeitos fixos, visando corrigir esses problemas de má especificação.

Apesar da existência de certo consenso de que existe a necessidade de estimar o modelo gravitacional em dados em painel para controlar a heterogeneidade, os pesquisadores divergem sobre qual seria a melhor forma de especificar o efeito fixo [ver Cheng e Wall (2004)]. Cheng e Wall (2004) argumentam que a forma como Bayoumi e Eichengreen (1995), Matyas (1997) e Glick e Rose (2001) não altera significativamente as estimativas dos coeficientes, contudo produzem resíduos viesados e maiores, gerando, dessa forma, imprecisas previsões dos fluxos comerciais. Além disso, elas não têm suporte estatístico e nem fundamentação na teoria econômica. Portanto, eles concluem que um efeito fixo para cada par de países e outro efeito fixo específico em cada ano $t$ deve ser a especificação utilizada.

Baldwin e Taglioni (2006) e, mais recentemente, Magee (2008), sugerem uma forma alternativa de especificação. A ideia é inserir três efeitos fixos, um para as características não observadas que são constantes no tempo para os pares de países, outro efeito fixo específico do tempo $t$ para cada importador $j$ e, por fim, um efeito fixo específico do tempo $t$ para cada exportador $i$. Entretanto, esta abordagem traz algumas desvantagens ao ser implementada. A primeira é que não é possível estimar o impacto de duas variáveis fundamentais dos modelos gravitacionais, o PIB e a população. 
Além disso, o principal inconveniente desta especificação é que ela impossibilita incluir dummies para mensurar o desvio de comércio. Nesse sentido, a especificação do efeito fixo utilizada neste trabalho seguirá a abordagem de Cheng e Wall (2004), que inclui um efeito fixo para características que são constantes ao longo do tempo para os pares de países e outro para capturar choques específicos em cada tempo $t$ que não foram percebidos pelas variáveis gravitacionais.

As controvérsias em relação ao modelo gravitacional também foram estendidas aos seus estimadores. Santos Silva e Tenreyo (2006) e Magee (2008) defendem a utilização do estimador da Pseudo Máxima Verossimilhança de Poisson (PMVP), enquanto Cheng e Wall (2004) e Baldwin e Taglioni (2006) trabalham com o estimador de Efeitos Fixos (LSDV). Por outro lado, o estimador de Hausman Taylor (HT) foi utilizado por Egger (2005) e Carrere (2006). Ainda, Egger (2002) utilizou o estimador Between para encontrar os coeficientes de longo prazo para o modelo. ${ }^{2}$ Percebe-se que, de fato, tais estimadores vêm produzindo resultados divergentes entre si e, por isso, ainda há um intenso debate sobre qual deles seria o mais indicado à equação gravitacional. Dessa forma, este artigo compara os resultados encontrados por esses estimadores (PMVP, LSDV, HT e Between), além do MQO com dados agrupados.

Por fim, para tentar contornar os efeitos da possível existência de parceiros naturais de comércio, considerar a resistência multilateral e o isolamento dos países e lidar com uma possível heterogeneidade bilateral, faz-se necessário estimar o modelo gravitacional com dados em painel e dois efeitos fixos. O primeiro deles é inserido no modelo para absorver todas as características observadas e não observadas que são constantes ao longo do tempo, mas que influenciam os fluxos bilaterais. Assim, ele levará em conta inclusive as variáveis observáveis que usualmente são utilizadas na equação gravitacional, tais como a distância entre os países, a extensão da área territorial do importador e do exportador, as dummies de fronteira, litoral e idioma em comum, além dos aspectos não observados, como laços históricos, culturais ou políticos e a possibilidade dos países serem parceiros naturais de comércio. Ao levar em conta todas essas característi-

2 Utilizando simulações de Monte Carlo, Pirotte (1999) apud Baltagi (2008, p. 220) mostrou que o limite em probabilidade do estimador Between para painel estático converge para os parâmetros de longo prazo. A única condição para que isso ocorra é a de que o número de indivíduos tenda ao infinito, mantendo fixo o período de tempo, e que os coeficientes do modelo sejam homogêneos entre as unidades individuais. 
cas, controla-se a heterogeneidade. O segundo efeito fixo captura choques não observados, comum a todos os países, que ocorrem em cada ano $t$ e que não foram percebidos pelas variáveis incluídas no modelo, mas que também podem determinar mudanças nos fluxos de comércio. Entre esses se encontram: o ciclo de negócios, fatores climáticos, guerras, entre outros.

\section{A Origem e o Tratamento dos Dados}

A amostra utilizada engloba 64 países para um período de 20 anos, de 1990 a $2009 .{ }^{3}$ Estas nações representavam, em termos de comércio mundial, aproximadamente $80 \%$ das importações mundiais totais para o período analisado. O trabalho apresenta 4.032 observações anuais (64 países importadores x 63 fluxos de importação bilateral) e 80.640 observações para todo período (4.032 observações $\mathrm{x}$ 20 anos). A variável dependente, importações bilaterais em dólares americanos correntes, foi obtida a partir do UN COMTRADE. ${ }^{4}$ Já o PIB dos países, também medido em dólares americanos correntes, e a população foram obtidos do Banco Mundial. ${ }^{5}$ A distância em quilômetros foi obtida do CEPII. A área em $\mathrm{km}^{2}$ também tem origem nesta mesma fonte, assim como as dummies de fronteira, idioma, relações coloniais e países sem litoral. As dummies referentes aos APC analisados foram construídas pelos próprios autores.

3 A lista dos países incluídos na análise é a seguinte: Argentina, Brasil, Paraguai, Uruguai, Canadá, México, Estados Unidos, Peru, Equador, Bolívia, Colômbia, Venezuela, Cingapura, Filipinas, Indonésia, Malásia, Tailândia, Austrália, Nova Zelândia, Barbados, Jamaica, Trinidad e Tobago, Costa Rica, El Salvador, Guatemala, Nicarágua, Egito, Ilhas Maurício, Madagascar, Quênia, Islândia, Noruega, Suíça, Áustria, Finlândia, Suécia, Argélia, Marrocos, Omã, Tunísia, Alemanha, Bélgica, Chipre, Dinamarca, Espanha, França, Grécia, Holanda, Hungria, Inglaterra, Irlanda, Itália, Polônia, Portugal, Romênia, Chile, China, Coréia do Sul, Hong Kong, Índia, Israel, Japão, Macau e Turquia.

4 A escolha pelo uso das importações como variável dependente, ao invés das exportações, deve-se ao fato de que as importações tendem a ser mais confiáveis, uma vez que os países controlam mais rigorosamente suas importações do que suas exportações, dada a saída de divisas que elas geram.

5 Baldwin e Taglioni (2006) argumentam que a equação gravitacional estimada em dados em painel e com efeitos fixos para os importadores e exportadores deve utilizar valores nominais para as importações e PIB dos países. Sendo assim, o trabalho seguiu este caminho. 
Para obter os coeficientes estimados expressos diretamente em termos de elasticidade, o que facilita a interpretação dos parâmetros estimados, os dados originais podem ser transformados para forma log-linear. Entretanto, como a variável dependente apresentou valor igual a 0 em 3.457 observações, o que representa apenas 4,29\% do total da amostra, não é possível transformar estas observações em logaritmo. ${ }^{6}$ Todavia, a literatura aponta algumas soluções para contornar este problema. A estratégia mais usual empregada ao modelo gravitacional foi sugerida por Eichengreen e Irwin (1995), que propuseram expressar o logaritmo da variável dependente como $\left(1+m_{i j t}\right)$.

Por outro lado, outras opções já foram utilizadas para estimar o modelo gravitacional principalmente através de estimadores não lineares. Uma delas é estimar o modelo pelo método de tobit, com apenas a variável dependente em nível. Já Santos Silva e Tenreyo (2006) propõem estimar o modelo gravitacional através do estimador PMVP. Assim, em ambos estimadores não é necessário efetuar nenhuma alteração nos dados da variável dependente, uma vez que eles a utilizam em nível.

Todavia, Wooldridge (2010, p. 181) salienta que a transformação logarítmica proporciona diversas vantagens em comparação às estimativas geradas com as variáveis em nível. Primeiramente, quando a variável dependente for estritamente positiva, é provável que ela possua uma distribuição condicional heteroscedástica ou concentrada e o uso do logaritmo pode aliviar e, até mesmo, eliminar ambos os problemas. Não obstante, a transformação logarítmica pode estreitar a amplitude dos valores das variáveis, tornando as estimativas menos sensíveis a outliers. Dessa forma, a Figura 1 apresenta o blox plot das importações em nível e do logaritmo das importações considerando $\left(1+m_{i j t}\right)$ na parte $\left.a\right)$ e $\left.b\right)$, respectivamente.

${ }^{6}$ Caso o modelo proposto for estimado de forma linear. 
a) Box Plot das importações em nível.

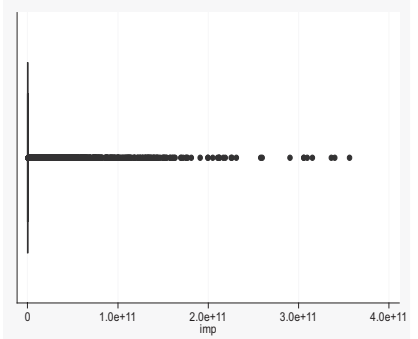

c) Box Plot das importações em nível excluindo valores inferiores a US\$6000,00 anuais

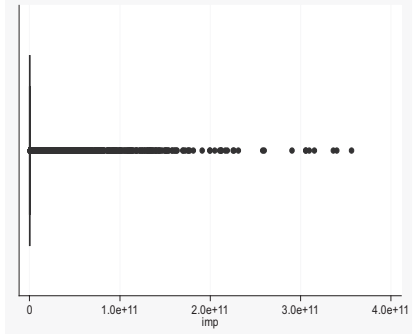

b) Box Plot do ln das importações.

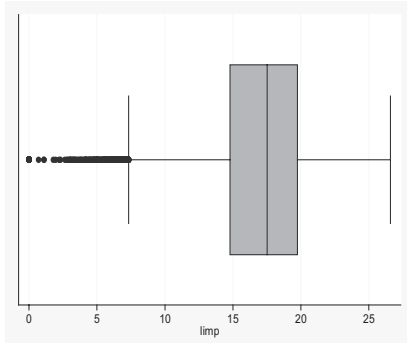

d) Box Plot do ln das importações excluindo valores inferiores a US\$ 6000,00 anuais

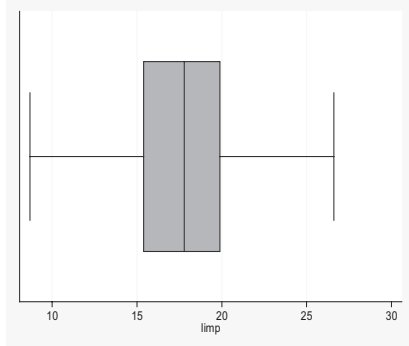

Figura 1 - Gráficos de histograma e box plot das importações em nível e após a transformação logarítmica

Fonte: Elaboração própria.

Percebe-se que a transformação logarítmica aliviou o problema da variável dependente possuir uma distribuição condicional heteroscedástica e muito concentrada ao produzir uma distribuição mais simétrica. Além disso, ela estreitou a amplitude da variável e isso tornou as estimativas menos sensíveis aos outliers, uma vez que o número de outliers, considerando as importações em nível, é muito superior em comparação aos dados logaritimizados. No entanto, mesmo com essa redução, outliers ainda estão presentes na variável em log e em nível, conforme pode ser observadas na Figura 1, partes a) e b).

Wooldridge (2010, p. 306) salienta ainda que os pesquisadores devem ficar atentos à presença de outliers, pois eles podem afetar fortemente as estimativas do modelo. Além disso, Hamilton (2009, p. 258-263) e Gujarati (2000, p. 470-471), argumentam que a presença de outliers pode mudar drasticamente não somente a magnitude, mas também os sinais dos coeficientes estimados pela regressão. 
Portanto, se eles estiverem presentes e a opção seja ignorá-los, isto é, caso eles não forem corretamente identificados e não recebam o devido tratamento necessário, especialmente na variável dependente, os resultados encontrados podem ser enganosos. Assim, a opção escolhida neste artigo foi retirar da amostra os outliers. ${ }^{7}$

Bussab e Morettin (2004, p. 48) sugerem uma forma fácil de identificar outliers utilizando justamente o gráfico Box Plot. Este gráfico é uma ferramenta muito útil na identificação dos mesmos, pois todos os pontos fora do limite inferior e superior (representados pelas linhas verticais da esquerda e da direita, respectivamente) podem ser considerados outliers. Para resolver o problema, foram excluídos da amostra os valores inferiores a 8,7 , considerando a variável em logaritmo natural, o que corresponde aproximadamente a importações anuais inferiores a US\$6.000,00. Portanto, quantias abaixo desse valor foram excluídas da amostra, resultando em uma perda de 4.704 observações, as quais representam apenas $5,8 \%$ do total da amostra. O painel d) da Figura 1, demonstra que esta medida eliminou completamente os outliers, considerando as importações em log natural, porém ela em nível permaneceu com o mesmo problema. ${ }^{8}$

Sendo assim, para os estimadores lineares, MQO, HT, LSDV e Between, a opção foi transformar os dados em logaritmo natural, excluindo as importações com valores inferiores a US\$6.000,00 anuais e, desta forma, aliviando o risco de viés, dada a presença dos outliers. Já para o estimador não linear utilizado, a variável dependente permaneceu em nível, no entanto, mesmo com a exclusão das importações com valores inferiores a US $\$ 6.000,00$ anuais, os outliers permaneceram presentes.

\footnotetext{
7 Os outliers podem ser originados de diversas formas e são eles que definem o tratamento mais correto a ser utilizado. Eles podem ocorrer: $i$ ) devido a erros nos dados, muitas vezes causados por erro humano durante a coleta dos dados, ii) em virtude de erros intencionais ou dados mal reportados, quando participantes, propositalmente ou não, relatam dados incorretos, iii) ou ainda decorrentes de erro de amostragem, quando alguns membros da amostra foram inadvertidamente tiradas de uma população diferente do resto da amostra, entre tantos outros motivos. Nos casos explicitados acima, a exclusão dos outliers não somente é aceita como é necessária. Assim, como é provável que isso ocorra com os dados de fluxos de comércio bilateral e com seleção dos países que compõem a amostra, a opção foi pela exclusão desses dados discrepantes.

8 Ao excluir tais observações, não foi necessário fazer qualquer transformação na variável dependente.
} 


\section{Os Modelos a serem Estimados e as Variáveis Utilizadas}

O PIB dos importadores e exportadores foi inserido no modelo como regressores, pois é de se esperar que quanto maior o PIB das economias envolvidas nos fluxos de comércio, maiores deverão ser as necessidades de consumo dos países importadores (dada a magnitude de suas rendas e ao tamanho de seus mercados) e maior será a diversidade de produtos na pauta de exportação dos países exportadores. Dessa forma, espera-se que o PIB apresente sinal positivo. Por outro lado, conforme salientaram Cheng e Wall (2004), não há consenso sobre o sinal esperado para o coeficiente da população a ser estimado. Para a distância, o modelo deverá estimar um coeficiente com valor negativo, uma vez que ela representa um fator de resistência ao comércio, pois quanto maior a distância entre dois parceiros comerciais, maior será o custo com fretes, o que torna os produtos mais caros e, consequentemente, reduziria os volumes de comércio.

No que se refere à área territorial, ela é inserida no modelo gravitacional, a fim de demonstrar a autossuficiência de cada nação em relação ao volume de comércio realizado com os demais países, pois é razoável supor que quanto maior a área de um país, maior será a sua disponibilidade de recursos naturais e, dessa forma, mais autossuficiente ele será e, portanto, menor sua necessidade de comercializar internacionalmente. Assim, espera-se que a área territorial obtenha um parâmetro estimado com sinal negativo.

Além dessas, variáveis dummies foram inseridas para captar aspectos como idiomas em comum, fronteira, relação colonial e países sem litoral. É natural pensar que países que possuem uma fronteira territorial em comum tenham uma propensão maior a trocar mercadorias do que aqueles que não as têm, pois entre ambos provavelmente há uma maior simetria em relação a gostos, costumes, leis e interesses comuns. Nesse caso, a dummy assume valor de 1 para os que possuem fronteira e 0 , caso contrário. Já países que não possuem litoral, acredita-se que o parâmetro estimado apresente um valor negativo, dado que a maior parte do comércio internacional ocorre através do transporte marítimo e, dessa forma, maior é a dificuldade de saída e chegada de mercadorias nos países que não possuem portos. Essa dummy assume o valor 1 para os países que não têm litoral e 0 para os demais. Um idioma em comum entre duas nações se torna um motivo adicional para ambas comercializaram um volume maior de 
comércio que aquelas que falam línguas diferentes, pois este fato gera uma maior facilidade de comunicação. Para os que possuem o mesmo idioma, o valor da dummy é l e, para países com idiomas diferentes, o valor é 0 . Por fim, uma dummy de relações coloniais assume valor 1 para países que tiverem ou têm ainda uma relação colonial e 0, caso contrário. Conforme analisado por Ghosh e Yamarik (2004, p.374), a literatura diverge sobre o sinal esperado para esta variável.

Seguindo a metodologia de Soloaga e Winters (2001), foram incluídas três variáveis dummies para cada APC, sendo uma delas para capturar o efeito da criação do APC sobre o comércio intrabloco, outra para as importações extrabloco e a última para as exportações extrabloco. Através da inserção dessas variáveis, será possível mensurar não somente o impacto nos fluxos de comércio que podem ser atribuídos à formação do bloco, mas também se há indícios de criação e desvio de comércio, bem como se ocorreu o que Soloaga e Winters (2001) denominaram de "desvio de exportação". Segundo Soloaga e Winters (2001), o desvio de exportação ocorre quando a formação do bloco diminui o bem-estar dos países não membros do bloco, através da redução do montante exportado para fora do bloco.

A Tabela 1 sintetiza como estas três variáveis em conjunto podem dar indícios de criação de comércio, desvio de comércio e desvio de exportação. Primeiramente, sabe-se que para ocorrer criação e desvio de comércio, há a necessidade de que o comércio intrabloco tenha sido alavancado. Neste sentido, o coeficiente estimado das importações intrabloco necessariamente precisa ser significativo e positivo. No caso específico da criação de comércio, a dummy das importações extrabloco deve apresentar um sinal positivo ou, no mínimo, não ser significativa. Apenas desta maneira, o comércio intrarregional não teria ocorrido em detrimento das importações do resto do mundo e, sendo assim, há indícios de criação de comércio. De forma contrária, sabe-se que o desvio de comércio pressupõe a substituição das importações extrabloco por importações de um parceiro comercial. Assim, haverá indícios de desvio de comércio quando conjuntamente o coeficiente das importações intrazona for positivo e significativo, e o coeficiente estimado para importações extrabloco apresentar um sinal negativo e significativo. Dessa forma, é possível mensurar a criação e o desvio de comércio em relação aos conceitos originais descritos por Viner (1950). 
Tabela 1 - Mensurando a criação, o desvio de comércio e o desvio de exportação

\begin{tabular}{l|c|l|c|l|c}
\hline \multicolumn{2}{c|}{ Criação de Comércio } & \multicolumn{2}{c|}{ Desvio de Comércio } & \multicolumn{2}{c}{ Desvio de Exportação } \\
\hline Variáveis & Sinal do Coef. & Variáveis & Sinal do Coef. & Variáveis & Sinal do Coef. \\
\hline Imp. Intrabloco & + & Imp. Intrabloco & + & Imp. Intrabloco & + \\
Imp. Extrabloco & + ou 0 & Imp. Extrabloco & - & Exp. Extrabloco & - \\
\hline
\end{tabular}

Fonte: Elaboração própria.

Nota: Coeficiente igual a zero expressa, neste caso, que ele não é significativamente diferente de zero.

Por fim, o conceito de desvio de exportação implica que as exportações extrabloco devem ser reduzidas devido à preferência dada em exportar para dentro do bloco. Neste sentido, para que este conceito seja mensurado de forma mais rigorosa, o bloco deve reduzir o montante exportado para fora do bloco, isto é, com a dummy de exportação extrabloco apresentando um sinal negativo e significativo e, paralelamente, as importações intrabloco deveriam aumentar com o coeficiente da dummy das importações intrabloco apresentando um sinal positivo e significativo. Somente assim, os países membros de um acordo comercial estariam deslocando suas exportações de fora do bloco para dentro do APC.

Parte-se agora para definir os modelos a serem estimados. A primeira equação gravitacional a ser estimada é a que representa a abordagem tradicional na qual utiliza dados agrupados e cujo estimador é o MQO. Esse modelo assume a seguinte forma: ${ }^{9}$

$$
m_{i j}=\beta_{0}+\sum_{k=1}^{N} \beta_{k} \cdot X_{i j}+\alpha_{t}+\varepsilon_{i j}
$$

onde:

$m_{i j}$ é vetor das importações bilaterais dos importadores $j$ e dos exportadores $i$;

$\beta_{0}$ é a constante;

$X_{i j}$ é o vetor com as $k$ variáveis gravitacionais (PIB, população, área, distância e demais dummies) dos importadores $j$ e ex portadores $i$;

9 Nesta estrutura de dados é possível estimar as variáveis que são constantes ao longo do tempo, tais como a distância entre a região $j$ e $i$, área territorial do importador e do exportador e as dummies de fronteira, idiomas, relação colonial e países sem litoral. 
$\beta_{k}$ é o vetor de parâmetros das variáveis $X_{i j}$;

$\alpha_{t}$ é o efeito fixo específico de cada ano $t$ que é comum para todos pares de países $i j$;

$\varepsilon_{i j}$ é o vetor de resíduos randômicos.

Já as equações em painel estático a serem estimadas através dos estimadores de LSVD, HT, PMVP e Between são representadas pela Equação 3. Porém, alguns detalhes devem ser salientados. Os estimadores HT e Between permitem estimar as variáveis que são constantes ao longo do tempo. Desta maneira, haverá dentro de sua matriz $X_{i j t}$ mais variáveis do que nas matrizes dos estimadores LSVD e PMVP e, consequentemente, no vetor $\beta_{k}$ haverá mais parâmetros. Já o estimador PMVP não estimará o valor da constante.

$$
m_{i j t}=\beta_{0}+\sum_{k=1}^{N} \beta_{k} \cdot X_{i j t}+\alpha_{t}+\alpha_{i j}+\varepsilon_{i j t}
$$

$m_{i j t}$ é vetor das importações dos países importadores $j$ e exporta dores $i$ no ano $t$;

$\beta_{0}$ é a constante;

$X_{i j t}$ é a matriz com as $k$ variáveis (PIB, população e dummies) dos importadores $j$ e exportadores $i$ no ano $t$;

$\beta_{k}$ é o vetor de parâmetros das variáveis $X_{i j t}$;

$\alpha_{i j}$ é o efeito fixo das características não observadas que são constantes no tempo para os pares de países $i j$;

$\alpha_{t}$ é o efeito fixo específico de cada ano $t$ que é comum para todos pares de países $i j$;

$\varepsilon_{i j t}$ é o vetor de resíduos randômicos do ano $t$.

Enfim, após definidas as variáveis que serão utilizadas e apresentadas as equações a serem estimadas (Equações 2 e 3 ) através de diferentes estimadores (MQO, LSDV, HT, PMVPP e Between), a próxima seção apresenta os resultados encontrados. 


\section{Resultados e Testes de Especificação}

Antes de apresentar os resultados encontrados, cabe ressaltar que o modelo foi submetido a vários testes. Para descobrir se é necessário controlar a heterogeneidade, foram realizados os testes de significância conjunta dos pares e de diferença entre os pares, além do teste conjunto para as dummies de tempo. Não obstante, para saber se as variáveis são correlacionadas com o efeito não observado, foi utilizado o Teste de Hausman. Os resultados indicam que é necessário controlar a heterogeneidade, conforme argumenta Egger (2005), sendo imprescindível utilizar dados em painel e efeitos fixos, conforme pode ser observado pelos resultados dos testes dispostos na Tabela $2^{10}$

Tabela 2 - Testes de especificação do modelo para painel

\begin{tabular}{l|c|c}
\hline Testes & Valor & p-valor \\
\hline Teste conjunto de significância dos Pares: F (4016, 71.872) & 67,68 & 0,000 \\
\hline Teste da diferença entre os Pares: F (4016, 71.891) & 34,88 & 0,000 \\
\hline Teste das Dummies de tempo: F (19, 76.276) & 162,90 & 0,000 \\
\hline Teste de Hausman: $\chi^{2}(47)$ & $3.109,38$ & 0,000 \\
\hline
\end{tabular}

Fonte: Elaboração própria.

Além disso, o critério de seleção utilizado para encontrar qual estimador seria o mais indicado à equação gravitacional foi o mesmo utilizado por Egger (2005). Segundo o autor, o estimador que apresentar o menor desvio padrão do erro de previsão do modelo será o que irá prever de forma mais satisfatória o comércio bilateral que teria ocorrido, caso os blocos não tivessem sido formados e, desta forma, seria o mais adequado. Neste sentido, pode-se adiantar que o estimador LSDV foi o que obteve melhor desempenho e, como ele foi o escolhido para analisar o impacto dos APC sobre os fluxos de comércio, este modelo foi submetido a mais alguns testes visando a testar sua robustez.

${ }^{10} \mathrm{O}$ Teste conjunto de significância dos pares verifica se os pares $\left(\alpha_{i j}\right)$ em conjunto são diferentes de zero. Sua hipótese nula é a de que eles em conjunto são iguais a zero. Já o Teste de diferença entre os pares foi baseado na proposta de Greene (2008, p. 197). Sua hipótese nula é a de que o efeito fixo é o mesmo para todos os pares. Dessa forma, não rejeitando a hipótese nula desses testes, dados agrupados devem ser utilizados, enquanto que nos casos de rejeição, dados em painel é a opção correta. Ainda, foi feito um teste F para as dummies de tempo e, através do Teste de Hausman, testado se efeitos fixos ou aleatórios são mais apropriados. 
Especificamente, o teste de heterocedasticidade groupwise foi utilizado para averiguar se a variância do erro é constante entre os pares de países [veja Greene, (2008, p. 172)]. Além disso, um teste de heterocedasticidade padrão foi realizado. ${ }^{11}$ Já visando a testar a presença de autocorrelação serial dos resíduos, o modelo foi submetido a três testes. O primeiro foi o teste de Wooldridge de autocorrelação [veja Wooldridge (2002, p. 282)], o segundo o de Durbin Watson modificado de Bhargava. Por fim, o terceiro estimou uma regressão auxiliar na qual apresenta o resíduo estimado como variável dependente e o resíduo defasado como variável independente, sem constante. Os resultados desses testes estão dispostos na Tabela 3.

Tabela 3 - Testes de especificação do modelo

\begin{tabular}{|c|c|c|}
\hline Testes & Valor & p-valor \\
\hline Teste de Wald mod. para heterocedasticidade groupwise: $\chi^{2}$ (4017) & 110000000 & 0,000 \\
\hline Teste de Hetocedasticidade padrão: F $(47,4.016)$ & 45,55 & 0,000 \\
\hline Teste de Autocorrelação de Wooldridge: $F(1,3932)$ & 525,183 & 0,000 \\
\hline Teste de Autocorrelação com regressão auxiliar de $e_{t}=e_{t-1}+V_{i j t}$ & 0,499 & 0,000 \\
\hline Durbin Watson modificado de Bhargava & 1,119 & ----- \\
\hline
\end{tabular}

Fonte: Elaboração própria.

Os testes de heterocedasticidade e autocorrelação indicaram a presença de resíduos correlacionados e erros não homocedásticos, pois as hipóteses nula dos testes foram fortemente rejeitadas a $99 \%$ de confiança. Assim, há a necessidade de estimar o modelo com a matriz de covariância de Arellano que, conforme Wooldridge (2002, p. 275), produz um erro padrão robusto mesmo com a presença de heterocedasticidade e autocorrelação serial dos resíduos, contanto que $\mathrm{T}$ seja relativamente pequeno em relação a N. ${ }^{12}$

${ }^{11}$ Esse teste de heterocedasticidade foi construído da seguinte forma: depois de estimado o modelo, utilizam-se seus resíduos ao quadrado como variável dependente e mantêm-se os mesmos regressores utilizados na primeira regressão, sem a constante e, dessa forma, é estimada uma segunda regressão. Em seguida, deve-se observar a significância estatística do teste F. Ao não rejeitar a significância conjunta dos regressores, os resíduos são homocedásticos.

${ }^{12}$ Como Baltagi $(2008$, p.1) salienta, pode-se considerar um micro painel quando há um grande $\mathrm{N}$ (usualmente na ordem de centenas ou milhares) para um curto período de tempo (que varia de 2 até, no máximo, 20 anos), como é o caso do presente trabalho. Não obstante, Hansen (2007b) apud Baltagi (2008, p. 16) estudou as propriedades do estimador LSDV e sua robusta matriz de covariância não somente quando $\mathrm{N}$ é grande, mas quando $\mathrm{T}$ também é. Ele demonstra que os erros robustos são consistentes quando $\mathrm{N}$ tende ao infinito independentemente do tamanho relativo de $\mathrm{N}$ em relação a $\mathrm{T}$ e mesmo na presença de resíduos equicorrelated. 
Os resultados encontrados por cada um dos estimadores utilizados se encontram na Tabela 4, salientando que eles são robustos, pois foram identificados os outliers existentes, sendo, logo após, excluídos da amostra e os erros padrão foram corrigidos para levar em conta a presença da heterocedasticidade e autocorrelação. Primeiramente, destaca-se que os estimadores HT, LSDV e PMVP refletem as estimativas dos parâmetros de curto prazo, ao passo que o estimador Between as de longo prazo, conforme Baltagi (2008, p. 219) argumenta. Uma vez que os testes anteriores indicaram a necessidade de controlar a heterogeneidade, o modelo com dados pooled não deve ser encorajado.

O estimador que apresentou o menor desvio padrão do erro de previsão do modelo, com apenas 0,7746 , e, dessa forma, foi o que obteve melhor desempenho, foi o LSDV. Assim, a análise dos resultados encontrados pelos demais estimadores de curto prazo é feita comparativamente tendo como referência o estimador LSDV. Antes ainda, cabe destacar que estimar o modelo gravitacional através MQO e dados agrupados, não controlando, assim, a heterogeneidade, superestima a importância do PIB do importador e exportador e subestima a relevância da população dos países em explicar os fluxos de comércio. Além disso, o MQO torna o impacto dos acordos preferenciais significativamente diferentes.

Por outro lado, os coeficientes encontrados pelo estimador de HT apresentaram sinais muito parecidos com os do estimador LSDV. Apenas duas variáveis, as dummies da União Europeia referentes às importações intrabloco e exportações extrabloco apresentaram coeficientes com sinais diferentes, muito embora eles não sejam significativos pelo estimador LSDV. Porém, o número de APC com coeficientes significativos obtidos pelo estimador HT foi muito superior ao encontrado pelo LSDV. ${ }^{13}$ Por fim, a PMVP superestimou o impacto do PIB dos importadores e exportadores, bem como os coeficientes das importações intrabloco do MERCOSUL, União Europeia e EFTA. Além disso, ele mudou o sinal do coeficiente estimado para a população do importador.

${ }^{13}$ Uma vez que o estimador HT é um estimador de variável instrumental, faz-se necessário testar se os instrumentos são válidos. Nesse exercício, o teste escolhido foi o teste de Sargan, que estabelece em sua hipótese nula que a condição dos momentos é válida. Dessa forma, para que os resultados do estimador HT sejam válidos, é necessário que não se rejeite a hipótese nula. Contudo, ela foi fortemente rejeitada a um nível de significância de 99\%, conforme pode ser observado na Tabela 4 . Portanto, ele também não deve ser utilizado. 
Tabela 4 - Resultados do modelo em um painel estático

\begin{tabular}{|c|c|c|c|c|c|c|c|c|c|c|c|c|c|c|c|}
\hline \multirow{2}{*}{ Variáveis } & \multicolumn{3}{|c|}{ MQO (Pooled) } & \multicolumn{3}{|c|}{ Hausman Taylor (HT) } & \multicolumn{3}{|c|}{ LSDV (Whitin) } & \multicolumn{3}{|c|}{ PMVP } & \multicolumn{3}{|c|}{ Between } \\
\hline & Coef. & $\sigma$ & & Coef. & $\sigma$ & & Coef. & $\sigma$ & & Coef. & $\sigma$ & & Coef. & $\sigma$ & \\
\hline PIB do Importador & 1,072 & 0,023 & * & 1,016 & 0,016 & * & 0,995 & 0,036 & * & 0,864 & 0,060 & * & 1,082 & 0,030 & * \\
\hline PIB do Exportador & 1,269 & 0,021 & * & 0,523 & 0,016 & * & 0,347 & 0,041 & * & 0,780 & 0,066 & * & 1,314 & 0,034 & * \\
\hline $\begin{array}{l}\text { População do } \\
\text { Importador }\end{array}$ & $-0,073$ & 0,031 & $\star *$ & 0,361 & 0,041 & * & 0,613 & 0,186 & * & $-0,843$ & 0,241 & * & $-0,086$ & 0,039 & ** \\
\hline $\begin{array}{l}\text { População do } \\
\text { Exportador }\end{array}$ & $-0,072$ & 0,031 & $\star *$ & 0,622 & 0,041 & * & 0,482 & 0,189 & * & $-0,305$ & 0,298 & & $-0,097$ & 0,043 & ** \\
\hline Área do Importador & $-0,073$ & 0,016 & * & $-0,283$ & 0,024 & * & - & - & & - & - & & $-0,050$ & 0,019 & * \\
\hline Área do Exportador & $-0,075$ & 0,017 & * & $-0,197$ & 0,024 & * & - & - & & - & - & & $-0,047$ & 0,020 & $* *$ \\
\hline Distância & $-0,997$ & 0,029 & * & $-1,136$ & 0,039 & * & - & - & & - & - & & $-1,073$ & 0,030 & * \\
\hline Importador sem litoral & $-0,180$ & 0,072 & $\star \star$ & $-0,141$ & 0,114 & & - & - & & - & - & & $-0,134$ & 0,068 & $\star \star$ \\
\hline Exportador sem litoral & $-0,091$ & 0,064 & & $-0,207$ & 0,113 & $\star \star \star *$ & - & - & & - & - & & $-0,075$ & 0,083 & \\
\hline Fronteira & 0,146 & 0,130 & & 0,269 & 0,195 & & - & - & & - & - & & 0,050 & 0,134 & \\
\hline Idioma em Comum & 0,809 & 0,063 & * & 0,625 & 0,091 & * & - & - & & - & - & & 0,874 & 0,073 & * \\
\hline Relação Colonial & 0,158 & 0,118 & & 0,589 & 0,191 & * & - & - & & - & - & & 0,068 & 0,134 & \\
\hline merc_imp_intra & 1,709 & 0,304 & * & 0,546 & 0,218 & ** & 0,341 & 0,188 & $\star \star \star *$ & 0,885 & 0,255 & * & 1,668 & 0,348 & * \\
\hline merc_imp_extra & $-0,118$ & 0,092 & & 0,290 & 0,054 & * & 0,321 & 0,085 & * & 0,689 & 0,070 & * & $-0,147$ & 0,106 & \\
\hline merc_exp_extra & 0,519 & 0,087 & * & $-0,062$ & 0,052 & & $-0,181$ & 0,080 & $\star \star$ & 0,030 & 0,056 & & 0,526 & 0,112 & * \\
\hline nafta_imp_intra & 0,126 & 0,503 & & 0,412 & 0,178 & ** & 0,353 & 0,128 & * & 0,245 & 0,081 & * & $-0,266$ & 0,689 & \\
\hline nafta_imp_extra & 0,271 & 0,095 & * & 0,327 & 0,033 & * & 0,317 & 0,068 & * & 0,101 & 0,075 & & 0,284 & 0,151 & $\star * \star$ \\
\hline nafta_exp_extra & $-0,544$ & 0,089 & * & 0,078 & 0,033 & ** & 0,028 & 0,046 & & $-0,146$ & 0,037 & * & $-0,898$ & 0,155 & * \\
\hline can_imp_intra & 1,640 & 0,181 & * & 0,255 & 0,153 & $\star \star \star \star$ & 0,217 & 0,342 & & 0,163 & 0,341 & & 1,700 & 0,191 & * \\
\hline can_imp_extra & $-0,109$ & 0,081 & & 0,245 & 0,054 & * & 0,316 & 0,125 & ** & 0,015 & 0,126 & & $-0,146$ & 0,104 & \\
\hline can_exp_extra & 0,079 & 0,089 & & 0,151 & 0,054 & * & 0,277 & 0,200 & & $-0,010$ & 0,078 & & $-0,037$ & 0,113 & \\
\hline asean_imp_intra & 2,407 & 0,151 & * & 0,360 & 0,128 & * & 0,296 & 0,125 & ** & 0,159 & 0,146 & & 2,657 & 0,166 & * \\
\hline asean_imp_extra & 0,659 & 0,085 & * & $-0,182$ & 0,037 & * & $-0,242$ & 0,072 & * & 0,001 & 0,051 & & 0,771 & 0,132 & * \\
\hline asean_exp_extra & 1,232 & 0,066 & * & 0,553 & 0,036 & * & 0,558 & 0,063 & * & 0,177 & 0,073 & $\star *$ & 1,383 & 0,093 & * \\
\hline anzcerta_imp_intra & 1,817 & 0,139 & * & 3,579 & 1,296 & * & - & - & & - & - & & 1,603 & 0,205 & * \\
\hline anzcerta_imp_extra & 0,257 & 0,135 & $\star \star \star \star ~$ & 1,061 & 0,187 & * & - & - & & - & - & & 0,312 & 0,190 & \\
\hline anzcerta_exp_extra & 0,585 & 0,137 & * & 1,831 & 0,187 & * & - & - & & - & - & & 0,557 & 0,134 & * \\
\hline caricom_imp_intra & 3,613 & 0,397 & * & 2,891 & 0,757 & * & - & - & & - & - & & 3,766 & 0,403 & * \\
\hline caricom_imp_extra & $-0,027$ & 0,101 & & 0,075 & 0,158 & & - & - & & - & - & & 0,073 & 0,116 & \\
\hline caricom_exp_extra & $-0,930$ & 0,141 & * & $-1,891$ & 0,160 & * & - & - & & - & - & & $-0,968$ & 0,144 & * \\
\hline
\end{tabular}


Tabela 4 - Resultados do modelo em um painel estático

(Continuação)

\begin{tabular}{|c|c|c|c|c|c|c|c|c|c|c|c|c|c|c|c|}
\hline \multirow{2}{*}{ Variáveis } & \multicolumn{3}{|c|}{ MQO (Pooled) } & \multicolumn{3}{|c|}{ Hausman Taylor (HT) } & \multicolumn{3}{|c|}{ LSDV (Whitin) } & \multicolumn{3}{|c|}{ PMVP } & \multicolumn{3}{|c|}{ Between } \\
\hline & Coef. & $\sigma$ & & Coef. & $\sigma$ & & Coef. & $\sigma$ & & Coef. & $\sigma$ & & Coef. & $\sigma$ & \\
\hline cacm_imp_extra & 0,054 & 0,095 & & $-0,026$ & 0,132 & & - & - & & - & - & & 0,014 & 0,090 & \\
\hline cacm_exp_extra & $-0,169$ & 0,113 & & $-1,432$ & 0,131 & * & - & - & & - & - & & $-0,209$ & 0,133 & \\
\hline comesa_imp_intra & 2,305 & 0,462 & * & 0,352 & 0,116 & * & 0,338 & 0,436 & & 0,206 & 0,475 & & 3,155 & 0,815 & * \\
\hline comesa_imp_extra & 0,196 & 0,090 & $\star \star *$ & $-0,216$ & 0,031 & * & $-0,252$ & 0,067 & * & $-0,248$ & 0,064 & * & 0,239 & 0,126 & $* \star *$ \\
\hline comesa_exp_extra & 0,056 & 0,095 & & $-0,158$ & 0,032 & * & $-0,074$ & 0,074 & & $-0,012$ & 0,110 & & 0,035 & 0,151 & \\
\hline ec_imp_intra & $-0,370$ & 0,095 & * & 0,091 & 0,042 & ** & $-0,008$ & 0,079 & & 0,241 & 0,086 & * & $-0,603$ & 0,137 & * \\
\hline ec_imp_extra & 0,118 & 0,065 & $* \star \star$ & $-0,316$ & 0,029 & * & $-0,356$ & 0,076 & * & 0,060 & 0,067 & & 0,347 & 0,085 & * \\
\hline ec_exp_extra & $-0,126$ & 0,062 & ** & 0,095 & 0,028 & * & $-0,010$ & 0,060 & & 0,122 & 0,070 & *** & $-0,090$ & 0,100 & \\
\hline efta_imp_intra & 0,261 & 0,306 & & 0,154 & 0,094 & & 0,011 & 0,107 & & 0,194 & 0,094 & $\star \star \star$ & 0,461 & 0,609 & \\
\hline efta_imp_extra & $-0,221$ & 0,098 & ** & $-0,011$ & 0,041 & & $-0,078$ & 0,092 & & 0,039 & 0,070 & & $-0,261$ & 0,164 & \\
\hline efta_exp_extra & $-0,112$ & 0,098 & & 0,164 & 0,041 & * & 0,069 & 0,070 & & 0,093 & 0,068 & & $-0,157$ & 0,171 & \\
\hline pafta_imp_intra & $-0,191$ & 0,320 & & 0,557 & 0,103 & * & 0,584 & 0,210 & * & 0,486 & 0,129 & * & $-0,772$ & 0,633 & \\
\hline pafta_imp_extra & $-0,095$ & 0,081 & & $-0,172$ & 0,026 & * & $-0,180$ & 0,055 & * & 0,165 & 0,043 & * & $-0,267$ & 0,192 & \\
\hline pafta_exp_extra & $-0,707$ & 0,107 & * & 0,156 & 0,027 & * & 0,213 & 0,076 & * & 0,040 & 0,069 & & $-1,640$ & 0,187 & * \\
\hline Constante & $-28,639$ & 0,542 & * & $-22,162$ & 0,765 & & $-34,676$ & 64,250 & * & - & - & & $-30,119$ & 9 0,710 & * \\
\hline № de observações & 75. & 936 & & & 936 & & 75.9 & & & & .925 & & 75.9 & 936 & \\
\hline $\mathrm{R}^{2}$ & 0,8 & 819 & & & 840 & & 0,90 & 907 & & & - & & - & & \\
\hline$F(64,4016)$ & 642,17 & $7[0.000]$ & & & - & & - & - & & & - & & - & & \\
\hline$F(47,4016)$ & - & - & & & - & & 205,45 & {$[0,000]$} & & & - & & - & & \\
\hline$F(45,3971)$ & 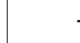 & - & & & - & & - & - & & & - & & $600,63[$ & {$[0,000]$} & \\
\hline Wald $\chi^{2}(64)$ & 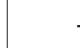 & - & & 47.604 & $97[0.000]$ & & - & - & & & - & & - & & \\
\hline Wald $\chi^{2}(47)$ & 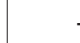 & - & & & - & & - & - & & 15.147 & $63[0,000]$ & & - & & \\
\hline $\begin{array}{l}\sigma \text { do Erro de Previsão } \\
\text { do Modelo }\end{array}$ & 1,4 & 1025 & & & 759 & & 0,77 & 746 & & & 6546 & & 0,90 & 099 & \\
\hline $\begin{array}{l}\text { Teste de Sargan } \\
\chi^{2}(24)\end{array}$ & 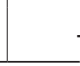 & - & & 1.235 & $5[0,000]$ & & - & - & & & - & & - & 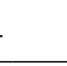 & \\
\hline
\end{tabular}

Fonte: Elaboração própria.

Notas: Erros robustos. Dummies de tempo anuais omitidas devido à falta de espaço. ${ }^{*},{ }^{* *},{ }^{* * *}$ denotam, respectivamente, nível de confiança de 99\%, 95\% e 90\%. As dummies bloco imp intra e bloco_imp_extra representam as importações intra e extrabloco, respectivamente, enquanto bloco_exp_extra representa as exportações extrabloco.

Os resultados encontrados pelo estimador Between revelaram um resultado já esperado, com os coeficientes de longo prazo do PIB do importador e exportador $(1,082$ e 1,314 , respectivamente) sendo superiores aos de curto prazo $(0,995$ e 0,347$)$. Além disso, no longo prazo, a população pouco influencia os fluxos de comércio bilaterais. 
Além disso, as variáveis distância, área do importador e exportador e idioma em comum foram significativas num nível de confiança de, no mínimo, 95\% e apresentaram coeficientes de acordo com o sinal esperado nos três estimadores que as possibilitam estimá-las (MQO, HT e Between).

Os coeficientes estimados pelo estimador LSDV das variáveis PIB e população, tanto para o importador quanto para o exportador, foram significativos a $99 \%$. Observa-se que um acréscimo de $10 \%$ no PIB dos países importadores provoca um aumento em suas importações em $9,95 \%$, e que para cada $1 \%$ de crescimento populacional, suas importações crescem em $0,61 \%$. Já um crescimento de $10 \%$ no PIB dos países exportadores faz com que eles aumentem suas exportações em $3,47 \%$. Por fim, um crescimento de $1 \%$ na população dos exportadores provoca um aumento em suas exportações de $0,48 \%$.

A análise das dummies que representam os APC sugerem alguns resultados interessantes. No que diz respeito ao Mercosul, os coeficientes estimados para as dummies de importação intra e extrabloco apresentaram um sinal positivo, e foram significativas a $90 \%$ e $99 \%$, respectivamente. Esta situação sinaliza que houve criação de comércio para o bloco. Além disso, como o coeficiente das exportações extrabloco apresentou um sinal negativo e foi estatisticamente significativo a um nível de confiança de 99\%, mostrando sinais de desvio de exportação, isto implica que as exportações extrabloco foram reduzidas devido à preferência dada em exportar para dentro do bloco, podendo, assim, reduzir o bem-estar dos países não membros do bloco. O comércio intrabloco no MERCOSUL foi, em média, 41\% superior ao do que o modelo gravitacional esperava. Muito embora a magnitude do coeficiente seja diferente, Cheng e Wall (2004) também encontraram que o MERCOSUL alavancou o comércio intrabloco em aproximadamente $61 \%$. As importações extrabloco foram 1,38 vezes maiores do que a equação predizia. ${ }^{14}$ Por outro lado, as exportações extrabloco foram $17 \%$, em média, inferiores ao que o modelo previa. De forma semelhante, o Nafta apresentou coeficientes positivos e significativos a $99 \%$ para suas importações intra e extrazona. Novamente, esses coeficientes em conjunto sugerem que houve criação de comércio. Porém, o impacto nas importações intrabloco foi levemente superior se comparado ao MERCOSUL, uma vez

${ }^{14}$ Dado que o modelo foi estimado em log, o coeficiente estimado para qualquer variável dummy é: [exp (coeficiente da dummy)]. Já seu percentual equivalente pode ser calculado da seguinte forma: [((exp (coeficiente da dummy))-1) x 100]. 
que as importações intrarregionais foram, em média, 42\% superiores ao do que o modelo gravitacional sinaliza. O Banco Mundial (2011) encontrou resultado semelhante para o Nafta. Ainda nas Américas, as dummies da Comunidade Andina (CAN) indicam que a formação do bloco em si não contribuiu para alavancar o comércio intrabloco durante todo o período, resultado este que contraria o encontrado por Magee (2008). Observa-se apenas que os países membros da CAN podem ser considerados países relativamente mais abertos ao livre comércio, pois suas importações extrabloco foram, em média, $37 \%$ superiores ao esperado.

As análises das dummies de importações do Asean e do Pan-Árabe Área de Livre Comércio (PAFTA) sugerem que esses blocos teriam desviado comércio, uma vez que o coeficiente de suas importações intrazona foi positivo e significativo, e que o coeficiente de suas importações extrabloco foi negativo e significativo. Destaca-se ainda a natureza exportadora do Asean, uma vez que suas exportações extrarregionais foram, em média, 74\% maiores do que o modelo presumia. Esses resultados para o Asean são semelhantes aos de Carrere (2006). De forma surpreendente, o PAFTA foi o acordo que mais alavancou o comércio intrabloco entre os APC analisados, uma vez que suas importações ficaram $79 \%$, em média, acima do que se podia esperar pelo modelo gravitacional.

Em relação aos blocos europeus, a Associação Europeia de Livre Comércio (EFTA) não teve impacto algum sobre os fluxos de comércio intra e extrabloco. Este resultado foi parcialmente semelhante aos de Rieder (2006), que encontrou impacto positivo apenas sobre as importações intrabloco. De forma similar, percebe-se que União Europeia (UE) também não teve impacto sobre suas importações intrabloco para todo o período, dado que sua dummy intrazona não foi significativa. Assim, é muito provável que grande parte dos benefícios proporcionados pela formação deste bloco já foram desfrutados em um período anterior ao analisado, portanto, mesmo com o aprofundamento da integração e com o ingresso de novos países, a partir dos anos 1990, a UE não foi capaz de expandir seu comércio intrabloco. ${ }^{15}$ Ademais, os resultados sugerem ainda que é possível que este APC tenha um papel importante para que seus membros fiquem protegidos comercialmente do resto do mundo, uma vez que o

15 Isto não significa que os países que aderiram recentemente ao bloco não tenham se beneficiado de alguma forma do livre comércio intrazona, entretanto, como essas economias são relativamente pequenas em relação às demais, possivelmente esse efeito não foi percebido pelo modelo. 
coeficiente estimado de suas importações extrabloco apresentou um sinal negativo e significativo a $99 \% .{ }^{16}$ Nesse sentido, a UE importa de fora do bloco $30 \%$ a menos do que o modelo prevê, sendo similar, porém superior aos 12,5\% a menos que Rieder (2006) encontrou.

O impacto observado no Mercado Comum da África Oriental e Austral (COMESA) foi similar ao do encontrado na UE. Portanto, as importações intrabloco do COMESA foram $22 \%$ inferiores ao que o modelo gravitacional previa e que não ocorreu aumento no comércio intrabloco. Esse resultado é compatível ao encontrado por Magee (2008), que utilizou o estimador da PMVP e par de efeitos fixos, porém divergente aos encontrados pelo Banco Mundial (2011, p. 61), que encontrou um surpreendente impacto negativo sobre os fluxos de comércio intrabloco. Os resultados encontrados por Magee (2008) e pelo Banco Mundial (2011) para o NAFTA e para o MERCOSUL corroboram com a ideia de que há indícios de criação de comércio nesses blocos. Todavia, ambas as fontes sugerem que o ASEAN teria criado comércio e não desviado, como foi encontrado no presente trabalho. Uma possível explicação para esta diferença é que esses trabalhos utilizaram amostras, períodos e metodologias diferentes. Rieder (2006) encontrou evidências de desvio de comércio para a União Europeia que não se confirmaram no presente trabalho.

Os resultados apresentados até aqui permitiram mensurar o impacto médio dos blocos econômicos sobre os fluxos de comércio para todo o período analisado, 1990 a 2009. Entretanto, é interessante modificar a equação gravitacional para que se torne possível mensurar a dinâmica dos fluxos de comércio intrabloco dos APC no tempo, tanto antes quanto após eles terem iniciado. Essa estratégia permitirá mensurar o impacto dos APC em períodos específicos do tempo e o efeito antecipação. Para isto, ao invés de incluir apenas uma variável dummy por bloco para todo o período, deve-se incluir uma dummy para cada ano do acordo. A grande vantagem desta abordagem é que ela permite observar em quais momentos os blocos influenciaram os fluxos de comércio, bem como a magnitude de seus efeitos. Essa metodologia já foi utilizada, de forma semelhante por Carrere (2006) e Rieder (2006). Porém, estes trabalhos utilizaram períodos e metodologias diferentes. Assim, utilizando novamente o estimador LSDV e ao invés de apresentar os resultados desta abordagem em uma enorme tabela, foram construídos gráficos de cada acordo para

${ }^{16}$ Notoriamente a UE é um bloco protecionista no setor agrícola e, isto, pode explicar este resultado obtido. 
que se possa observar a evolução dos coeficientes intrabloco, bem como suas magnitudes. Dessa forma, a Figura 2 apresenta a evolução das dummies de seis APC, no que se refere às suas importações intrabloco e, a Figura 3, as dummies dos blocos europeus. Os pontos destacados representam apenas os coeficientes significativos a um nível de, no mínimo, 90\% de confiança. Além disso, as linhas superiores e inferiores tracejadas representam o intervalo de confiança dos coeficientes a 95\%, enquanto e as linhas tracejadas verticais representam o ano de formação do acordo ou alguma alteração que o mesmo passou naquele ano.

MERCOSUL

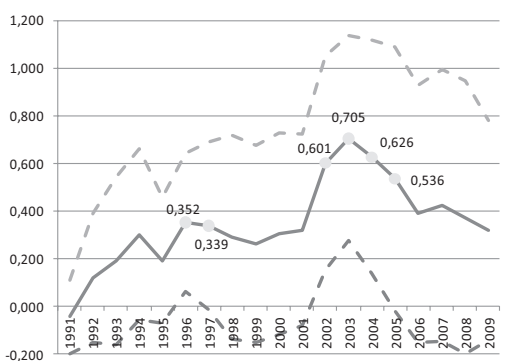

CAN

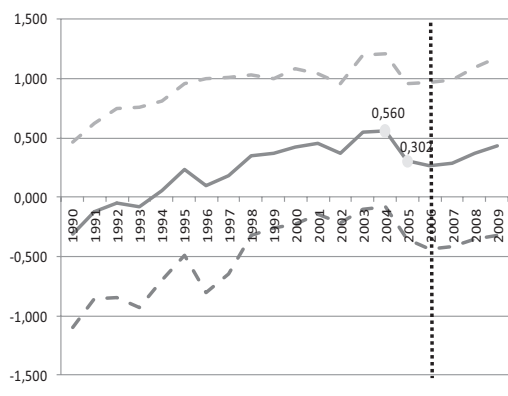

COMESA

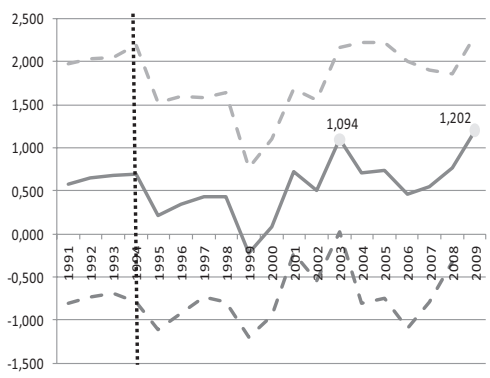

NAFTA

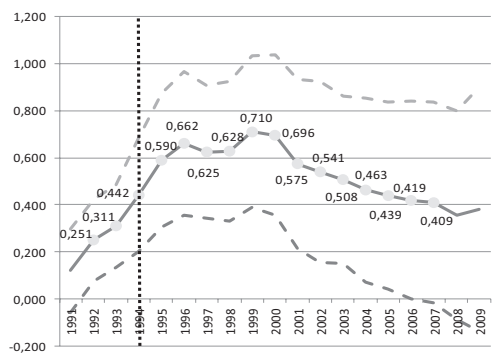

ASEAN

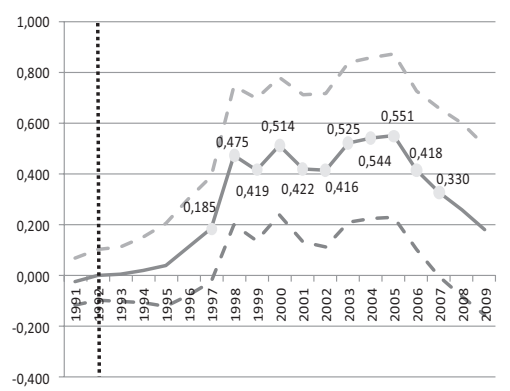

PAFTA

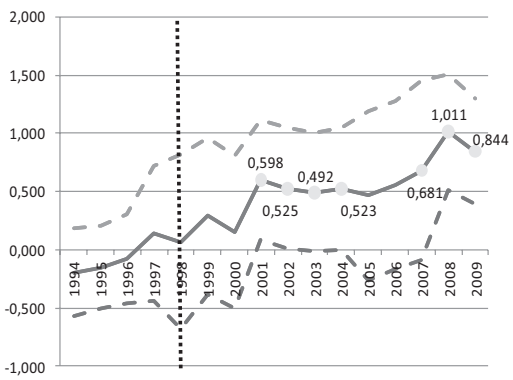

Figura 2 - A evolução das dummies intrabloco dos APC do novo regionalismo Fonte: Elaboração própria. 
Muitos resultados interessantes foram encontrados por essa abordagem. Primeiramente, dos 19 anos analisados, apenas em 6 o MERCOSUL teve impacto sobre os fluxos de comércio intrabloco. De forma surpreendente, observa-se ainda que o MERCOSUL conseguiu alavancar o comércio intrazona somente após seu quinto ano de constituição, mais especificamente nos anos de 1996 e 1997, quando a Área de Livre Comércio já estava estabelecida para a maioria dos seus produtos ${ }^{17}$ e durante o período no qual a União Aduaneira vinha sendo implementada. Este resultado vai ao encontro dos volumes de comércio que vinham sendo realizados entre seus países membros, uma vez que foi no ano de 1997 que o comércio intrabloco chegou ao seu pico da década, num total de US\$20,5 bilhões. Logo após este período, o coeficiente intrarregional deixou de ser significativo novamente. Por outro lado, Carrere (2006) encontrou um impacto positivo sobre os fluxos de comércio num período anterior ao mensurado por este trabalho, de 1990 até 1996.

O ano de 1998 foi marcado como o ano que ocorreu a primeira queda em valor absoluto no comércio intrabloco do MERCOSUL. Essa redução foi causada pela crise que se instalou nos países asiáticos, a partir de 1997 e da moratória russa de 1998, que proporcionaram um cenário internacional de recessão e desconfiança. Outros problemas surgiram após este período, em grande parte devido a crises internas dos membros do acordo. Em 1999, o Brasil foi obrigado a desvalorizar sua moeda. ${ }^{18}$ Em 2001, a Argentina entrou em profunda recessão e seu PIB chegou a retroceder a um nível menor do que nove anos antes e o seu risco-país disparou, gerando um default dos seus títulos da dívida pública. Não obstante, o Brasil enfrentou um ataque especulativo contra sua moeda em 2002 que, nesta oportunidade, foi forçada a se desvalorizar significativamente mais uma vez. Dessa forma, tal conjuntura corrobora com os resultados estimados pelo modelo de que, no período de 1998 a 2001, o bloco não teria tido impacto sobre o comércio intrabloco, uma vez que tal período foi marcado por fortes crises externas ou internas nos países participantes do bloco, que levaram à adoção de medidas protecionistas que afetaram o comércio intrabloco.

\footnotetext{
${ }^{17}$ Alguns produtos não usufruem de um livre comércio dentro do bloco até hoje, tais como o regime automotivo, açúcar e produtos da linha branca.

${ }^{18}$ Com a desvalorização cambial, ocorreu uma grande mudança nas relações de competitividade entre as economias do bloco, tornando os produtos brasileiros mais baratos em relação aos demais membros.
} 
Passado o período de turbulência, o MERCOSUL voltou a apresentar impacto sobre o comércio intrabloco, a partir de 2002 até 2005. Desta vez, a possível explicação passa pelo fato de que a Argentina elevou suas importações dos países membros do bloco. Suas importações intrazona que representavam aproximadamente $31 \%$ do seu total, em 2001, passaram para 42\%, em 2005. De forma semelhante, porém menos intensa, isso aconteceu com o Uruguai durante o mesmo período. Além disso, foi no ano de 2003 que o coeficiente estimado para as importações intrabloco atingiu seu maior nível $(0,705)$, que representa aproximadamente um comércio 102\% maior do que o modelo previa naquele ano.

No Nafta, que foi formado em 1994, percebe-se a presença do efeito antecipação sobre os fluxos de comércio dois anos antes de o bloco ter sido formado. Dessa forma, mesmo antes do bloco ter sido constituído formalmente, Estados Unidos, Canadá e México comercializaram, entre 1992 e 1993, respectivamente, 29\% e 36\% a mais que o modelo previa. A explicação está no fato de que os Estados Unidos e Canadá já haviam assinado um Acordo Preferencial de Comércio antes da formação do Nafta. Além disso, de todos os blocos analisados, o Nafta foi que o apresentou o efeito mais duradouro sobre o comércio intrabloco, uma vez que seu impacto já foi percebido dois anos antes de sua constituição e durante os 14 anos seguintes. Assim, este resultado contradiz o encontrado por Krueger (1999), que concluiu que o Nafta não teve um grande impacto sobre o comércio nos seus primeiros três anos de existência.

Em relação à Comunidade Andina, o impacto sobre os fluxos de comércio foi muito modesto, e ocorreu dois anos antes da saída de um de seus principais participantes, a Venezuela. Assim, somente nos anos de 2004 e 2005, a CAN aumentou o comércio intrabloco em, aproximadamente, $75 \%$ e $35 \%$, respectivamente. No entanto, este resultado é completamente distinto do encontrado por Carrere (2006), que encontrou dummies positivas para o comércio intrabloco de 1970 até 1996. De forma semelhante, o impacto que pode ser atribuído ao COMESA também foi em dois períodos pontuais, apenas após seu $9^{\circ}$ e $15^{\circ}$ ano de constituição. Por outro lado, o Asean e o PAFTA apresentaram um impacto mais significativo sobre o comércio intrazona, entretanto sem a existência do efeito antecipação. Após o estabelecimento da Área de Livre Comércio no Asean, em 1992, seus fluxos de comércio intrabloco foram alavancados somente após 
seu $5^{\circ}$ ano de formação. Além disso, percebe-se que este impacto foi mais duradouro do que no MERCOSUL, uma vez que perdurou, ininterruptamente, durante 11 anos. Esse resultado é também difere do encontrado por Carrere (2006), que mensurou um impacto positivo no comércio intrabloco de 1978 até 1996. Já o impacto do PAFTA foi mais rápido sobre o comércio intrarregional, uma vez que ele ocorreu após seu $3^{\circ}$ ano de formação. Entretanto, ele teve uma interrupção durante os anos de 2005 e 2006. A Figura 3 apresenta os gráficos dos APC europeus que surgiram durante a primeira onda do regionalismo, mas que tiveram algumas transformações na segunda. Percebe-se que mesmo com os sucessivos alargamentos, em 1995, 2004 e 2007, os fluxos de comércio intrazona da UE parecem já ter atingido seu patamar máximo, dado que em apenas 2 dos 20 anos analisados observa-se um impacto.

A dummy positiva do ano de 2000 coincide com o período no qual estava sendo estabelecida uma moeda única entre alguns dos Estados Membros da UE. Assim, era provável que a criação do Euro estimulasse os fluxos de comércio ao extinguir os riscos de perdas com flutuações cambiais e ao minimizar os custos existentes com fechamento de câmbio. Já o impacto positivo de 1990 pode ser em decorrência ainda do Ato Único Europeu, que estabeleceu um cronograma para resolver alguns entraves que dificultavam o livre comércio no bloco. De forma contrária, a EFTA apresentou um impacto negativo durante 5 anos, de 2002 a 2005, além de 2007. Salientam-se ainda que mesmo após 5 anos da saída da Áustria, Finlândia e Suécia em 1995, nenhum impacto foi observado sobre o comércio intrazona.

\section{UNIÃO EUROPEIA}

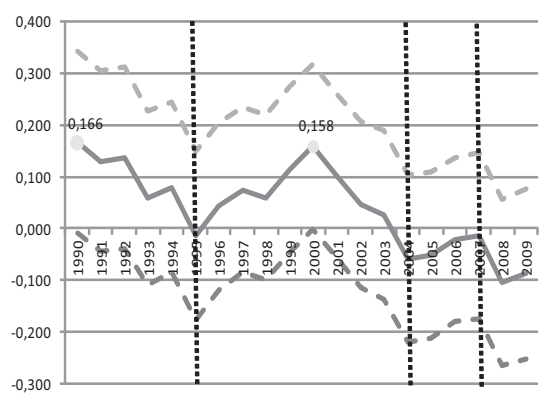

EFTA

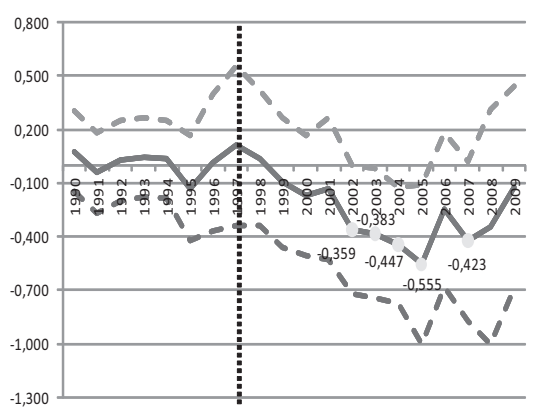

Figura 3 - A evolução das dummies intrabloco dos APC europeus

Fonte: Elaboração própria. 
Dessa forma, este trabalho avançou na mensuração do efeito antecipação se comparado ao estudo de Magee (2008), pois aqui, como no estudo de Carrere (2006), foi possível mensurar esse efeito em alguns blocos e não nos APC como um todo. Assim, entre os blocos analisados, apenas no Nafta foi identificado este efeito, sendo esse resultado similar ao que Carrere (2006) encontrou para o bloco.

Por fim, a impressão que se tem ao observar o grande percentual que as importações intrabloco da UE têm sobre suas importações totais, na faixa de $60 \%$ a $70 \%$ para o período analisado, seria consequência da existência do bloco, foi desmistificada pelos resultados encontrados, uma vez que eles sugerem que o aumento no comércio intrazona de 1990 a 2009 foi de apenas 35\% que, em termos médios, representa somente $1,8 \%$ ao ano.

Assim, é provável que grande parte dos benefícios proporcionados pela liberalização do comércio tenham sido desfrutados em um período anterior ao analisado, portanto, mesmo com o aprofundamento da integração e com o ingresso de novos países, a partir dos anos 1990, a UE não foi capaz de expandir seu comércio intrabloco. Aliado a isso, a EFTA reduziu o comércio intrabloco, em média 8,8\% ao ano.

\section{Conclusão}

Este artigo teve como objetivo principal mensurar quais foram os impactos da criação dos APC sobre os fluxos de comércio intra e extrabloco no período 1990-2009, e se o novo regionalismo propiciou criação ou desvio de comércio aos seus participantes, bem como se ocorreu desvio de exportação. Para isto, utilizou-se o modelo gravitacional com dados em painel e efeitos fixos. Não obstante, dada a controvérsia existente de qual estimador é o mais adequado ao modelo, o artigo comparou o MQO (pooled), LSDV, HT, PMVP e Between e sugere que neste estudo o LSDV seria o mais apropriado. Ademais, percebeu-se que a equação gravitacional é extremamente sensível a presença de outliers.

A análise das dummies dos APC sugere que houve criação de comércio com a formação do MERCOSUL e do Nafta, enquanto o desvio de exportação foi observado somente no MERCOSUL. 
Por outro lado, indícios de desvio de comércio foram encontrados no Asean e no PAFTA. Destaca-se ainda o dinamismo exportador de ambos os APC. Os resultados para a CAN e para EFTA indicam que tais acordos não alavancaram o comércio intrabloco. Já os níveis de comércio intrazona da União Europeia parecem que chegaram ao seu limite, dado que o bloco não alavancou suas importações intrabloco. A mesma situação foi observada no COMESA. Assim, é possível que estes dois APC tenham um papel importante para que seus membros fiquem protegidos comercialmente do resto do mundo, uma vez que o coeficiente estimado de suas importações extrabloco apresentou um sinal negativo e significativo a $99 \%$.

A escolha do indicador para medir os efeitos da integração regional é crucial. Geralmente, assim como fez este artigo, a ênfase tem sido dada a variáveis intermediárias, especialmente o comércio. Nesse sentido, mais de 50 anos após a contribuição original de Viner (1950), os instrumentos vinerianos - desvio e criação de comércio - ainda são extremamente úteis para se mensurar os impactos da integração. No entanto, exercícios de criação (desvio) de comércio são apenas medidas indicativas e não definitivas de ganhos (perdas) de bem-estar. Alguns autores são ainda mais radicais, como Waelbroeck apud Sapir (1992), que sugeriu que o comércio internacional só mereceria destaque pelos impactos que ele traria sobre as principais variáveis de política econômica, como o bem-estar e a distribuição de renda. Finalizando, possivelmente a contribuição mais importante deste artigo foi constatar que a dinâmica dos fluxos de comércio intrabloco (tanto ex ante quanto ex post a constituição dos APC) foi diferente não somente em termos de volume e duração, mas também na velocidade em que eles responderam a sua formação, isto é, seus efeitos foram percebidos imediatamente em alguns blocos e em outros eles demoraram alguns anos. Ainda, o temor de que o mundo estaria ficando mais regionalizado, dado o boom de blocos econômicos formados a partir de 1990, parece que tem sido demasiado, pois, a partir dos resultados encontrados, há evidências de que o regionalismo ocorreu simultaneamente à liberalização multilateral na maioria dos APC analisados. 


\section{Referências}

AITKEN, N. The effect of the ECC and EFTA on European trade. A temporal cross-section analysis. American Economic Review, v. 63, p. 881-892, 1973.

ANDERSON, J.E., VAN WINCOOP, E. Gravity with Gravitas: A Solution to the Border Puzzle. American Economic Review, v. 93, p. 170- 192. 2003.

BALDWIN, R. TAGLIONI, D. Gravity for Dummies and Dummies for Gravity Equations. NBER Working Paper $N^{o}$ 12516. 2006.

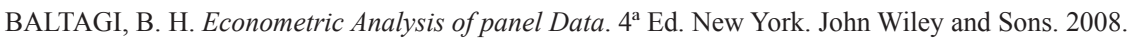

BANCO MUNDIAL. Preferential Trade Agreement Polices for Development: A Handbook. Jean-Pierre Chauffor e Jean-Christophe Maur (Ed). Washington. The World Bank. 2011.

. World Development Indicators. Portal Oficial. Disponível em: $<$ http://data.worldbank.org/data-catalog/world-development-indicators> Acesso em: 20. Set. 2011.

BAYOUMI, T., EICHENGREEN, B. Is regionalism simply a diversion? Evidence from the evolution of the EC and EFTA. NBER Working Paper $N^{o}$ 5283. 1995.

BHAGWATI, J., KRISHNA, P., PANAGARIYA, A. (Ed). Trading Blocs: Alternative Approaches to Analyzing Preferential Trade Agreements. Cambridge. London. The MIT Press. 1999.

BUSSAB, W. O., MORETTIN, P. A. Estatística Básica. 5ª Ed. São Paulo. Saraiva. 2004.

CARRERE, C. Revisiting the effects of regional trade agreements on trade flows with proper specification of the gravity model. European Economic Review, v. 50, p. 223-247. 2006.

CENTRE D'ETUDES PROSPECTIVES ET D'INFORMATIONS INTERNATIONALES (CEPII). Disponível em: <http://www.cepii.fr/> Acesso em: 19 Jun. 2011.

CHENG, H. WALL, H.J. Controlling for Heterogeneity in Gravity Models of Trade and Integration. Federal Reserve Bank of St. Louis Working Paper No 1999-010. 2004.

EGGER, P. An Econometric View on the Estimation of Gravity Models and the Calculation of Trade Potentials. The World Economy, v. 25, Issue 2, 2002.

. Alternative Techniques for Estimation of Cross-Section Gravity Models. Review of International Economics, v. 13 (5), p. 881-891, 2005.

EICHENGREEN, B. IRWIN, D. Trade Blocks, Currency Blocs, and the Reorientation World Trade in the 1930's. Journal of International Economics, v. 38, p. 1-24. 1995.

GHOSH, S., YAMARIK, S. Are regional trading arrangements trade creating? An application of extreme bounds analysis. Journal of International Economics, v. 63, p. 369-396. 2004.

GLICK, R. ROSE, A.K. Does a Currency Union Affect Trade? The time series evidence. NBER Working Paper $N^{\circ}$ 8396. 2001.

GREENE, W. H. Econometric Analysis. $6^{\mathrm{a}}$ Ed. New Jersey. Pearson Prentice Hall. 2008.

GUJARATI, D. N. Econometria Básica. $3^{\mathrm{a}}$ Ed. São Paulo. Pearson Education. 2000.

HAMILTON, L.C. Statistics with Stata: Updated for Version 10. $7^{\mathrm{a}}$ ed. Canada. Cengage Learning. 2009.

KRUEGER, A. Trade Creation and trade diversion under Nafta. NBER Working Paper No 7429. 1999.

KRUGMAN, P. The move toward free trade zones. Economic Review, Federal Reserve Bank of Kansas City, 76, Kansas City, p. 5-25. 1991.

LINNEMANN, H. An Econometric Study of International Trade Flow. Amsterdam: North-Holland, 1966.

LIPSEY, R. The Theory of Customs Unions: Trade Diversion and Welfare. Economica, v. 24, p. 40-43, 1957.

MAGEE, C. New Measures of Trade Creation and Trade Diversion. Journal of International Economics, v. 75 , p. $340-362.2008$.

Estud. Econ., São Paulo, vol. 44, n.2, p. 351-381, abr.jun. 2014 
MATYAS, L. Proper Econometric Specification of the Gravity Model. The World Economy, v. 20, p. 363-68, 1997.

MEADE, J. The Theory of Customs Unions. Amsterdam: North-Holland, 1955.

PANAGARIYA, A. The Free Trade Area of Americas: good for Latin America? World Economy, v. 19, p. 485-515, 1996.

POYHONEN, P. A tentative model for the volume of trade between countries. Weltwirtschatftliches Archiv, v. 90, p. 93-99, 1963.

RIEDER, R. An empirical Analysis of the Domino Theory for the EU, 1962-2004. Institute of International Studies Geneva. HEI Working Paper 11. 2006.

SANTOS SILVA, J.M.C., TENREYO, S. The log of gravity. Review of Economics and Statistics, v. 88, p. 641-658. 2006.

SAPIR, A. Regional integration in Europe. The Economic Journal, v. 102, p. 1491-1506, 1992.

SOLOAGA, I.; WINTERS, L. A Regionalism in the nineties: What effect on trade? The North American Journal of Economics and Finance, v. 12, p. 1-29, 2001.

SUMMERS, L. Regionalism and the World Trade System. Economic Review, Federal Reserve Bank of Kansas City0, 76, Kansas City, pp. 295-302. 1991.

TINBERGEN, J. Shaping the World Economy: Suggestions for an International Economy Policy. New York. Twentieth Century Fund, 1962.

UN COMTRADE. UN Commodity Trade Statistics Database. Statistical Division of the United Nations. Disponível em: <http://comtrade.un.org/> Acesso em: 26 Ago. 2011.

VINER, J. The Customs Union Issue. New York. Carnegie Endowment for International Peace. 1950.

WINTERS, L. A. Assessing Regional Integration Arrangements. Paper prepared for the third annual World Bank conference on development in Latin America and the Caribbean, Trade: Towards open regionalism, Montevideo, Uruguay, 1997.

WONNACOTT, P., LUTZ, M. Is there a case for free trade agreements? em: Schott, J. (Ed.), Free Trade Areas and U.S. Trade Policy. Institute for International Economic. Washington. 1989.

WOOLDRIDGE, J.M. Econometric Analysis of cross section and panel data. Cambridge. The MIT Press. 2002.

. Introdução à Econometria: Uma abordagem Moderna. $4^{\mathrm{a}}$ ed. São Paulo. Cengage Learning. 2010.

YEATS, A. Does Mercosur's trade performance raise concerns about the effects of Regional Trade Arrangements? Washington, DC: World Bank, 1997 (Policy Research Work Paper, n. 1729). 